\title{
Perceived Barriers Of E-Commerce Expansion In The Electronic Manufacturing Companies In Malaysia
}

\author{
Syed Shah Alam, (Email: wsteah@mmu.edu.my), Multimedia University, Malaysia \\ Ali Khatibi, (E-mail: ali.khatibi@mmu.edu.my), Multimedia University, Malaysia \\ Chloe Teah Woon Sim, (E-mail: wsteah@mmu.edu.my), Multimedia University, Malaysia \\ Ahasanul Haque, Multimedia University, Malaysia
}

\begin{abstract}
This study examines the major barriers that prevent manufacturing companies in Malaysia from adopting e-commerce. The major barriers of e-commerce expansion were security of payment and uncertain nature of legal and regulatory frameworks. Also the empirical findings reveal that doing business over Internet involves high start-up cost. In fact it is costly to set-up business electronically, because so many technological appliances are involved. Computers are quite expensive to buy limited maintenance facility issue to take advantage of EC. This issue is really affecting small businesses. Therefore, in order to attract and motivate the adoption of EC, the government has to support this sector fully by providing bank loans or subsidiaries.
\end{abstract}

\section{Introduction}

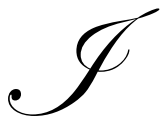

$\mathrm{t}$ is increasingly widely accepted that it is important for business to embrace e-commerce and to adopt Internet technologies. E-commerce technologies include searching for products, services and information, advertising, and the buying, selling and paying for products and/or services. It is established that e-commerce technologies provide a cost-effective way for organisations to market their business, launch new products, improve communications, gather information, and identify potential business partners.

The value of worldwide EC is expected to reach by 2004, range from a prediction of $\$ 963$ billion by ActiveMedia Researcher to Forester Research's prediction of \$4 trillion and IDC Research projects spending will reach $\$ 2.8$ trillion (e-commercetimes). Despite this high potential, Asian businesses are still reluctant to infuse EC into their business process. Asia as a whole appears less engaged in EC compared to the United States and Europe. One apparent explanation could be that many Asian countries tend to be less developed than Western countries. A more complete explanation of the lag, however, must include related problems that Asian penetration, inefficientlymanaged telecom monopolies, language barriers, hierarchical corporate cultures, and often intrusive and bureaucratic governments (Anderson, 1998).

In spite of inertia, several Asian countries (e.g. Hong Kong, Malaysia, and Singapore) are in the process of creating IT infrastructure that will facilitate EC innovation and are attempting to remove the above-mentioned barriers. These countries are aware that the next several years will see tremendous growth in business-to-business networks in order to maximise resources and economise on costs given the potential offered by EC. Businesses that fail to take advantage of technological advances will decline (Dryden, 1998).

Malaysia has already considerably shifted her agriculture based economy to industry based one in order to stand the challenge of the twenty first century. The latest industrial initiative taken by the Malaysian Government after 1997 was to encourage the firms that are more knowledge-intensive than production-intensive in order to transform Malaysia into a country based on knowledge-economy (K-economy). Malaysia's workforce are well on the right track to make their economy on information dominated one. The employment opportunity create by the 
information sector accounts for $28 \%$ of the total workforce at the end of 1998 and it is expected to grow $38 \%$ by the end of 2003 (Niles, 1999). The Multimedia Super Corridor (MSC) has, moreover, attracted much attention for the development and implementation of EC in the business.

Electronic commerce is being increasingly used by commercial firms or organisation to advertise and market both goods and services all over the world. Manufacturers of far-off countries can offer their products or services with information related to product capabilities and benefits, content or components, price, production schedules, delivery and payment conditions. The electronic industry in Malaysia has turned into a leading and major manufacturing sector contributing a largest share to the total manufacturing output, exports and employment. With the help of EC this sector can expand its market share in the global business arena. That is why, the adoption of electronic commerce, particularly the Internet as a platform for the business, is considered in this research.

\section{Literature Reviews}

This study fills a knowledge about EC diffusion in the electronic manufacturing companies in Malaysia, and to identify which are important for encouraging willingness to adopt EC. The research gap is found in the recent studies:

Most of the previous study found that security, privacy and hackers intervention are the main technical problems in EC trade which negatively affect it (Mukti, 2000; Udo 2001; Aldridge et al., 1997).

A study of Mukty (2000) surveyed 110 Malaysian companies on potential barriers of EC. This study reveals that lack of skilled IT personnel; limited telecommunication bandwidth and high set up cost, security, privacy and hackers intervention were main barriers of EC trade in Malaysia.

Bauman et al (1996) considered barriers of EC adoption are security, privacy and legal issues. These authors identify the most prevalent security threats when using EC and discuss some of the traditional and emerging approaches to ensuring data security and integrity on the Internet.

Steinfield and Klein (1999) argued that cultural factors inhibit the diffusion of e-commerce. They comment that cultural values, including different traditions and habits of trading will impact the speed of e-commerce diffusion. Clearly, cultural issues including beliefs, language and value systems seem to present barriers to information sharing.

\section{Purpose of Study}

The main purpose of this study is to investigate the major barriers perceived by the electronic manufacturing companies in Malaysia and to compare the major barriers between demographic groupings.

\section{Methodology}

Given the lack of empirical research in this area especially in Malaysia, an exploratory investigation was considered the most method (Churchill, 1991). The research method was adopted from the combination of qualitative and quantitative approach as suggested by Miles and Huberman (1994). This approach begins with initial qualitative survey and then followed up by detailed interviews. Unfortunately in Malaysia, there is no detail database about internet users in industry (Hamid and Baharun, 2002), stratified random sampling procedures were designed for this study.

The sample size derived for the Federation of Malaysian Manufacturer (FMM) 2000 listed members of electronic manufacturing companies in Penang and Klang Valley areas. The list included the company's total employees, annual turnover and year of incorporation of business. Due to the time and cost constraints it was not possible to collect the data to use a simple random sample from the original databases of the firms, and a stratified random sampling method was attempted in order to carefully identify firms from the two groups. The target groups 
were SMIs and large scale industry considered based on the number of employees in the industry is most commonly used in management research (Ghobadian and Gallear, 1996; Hakserver, 1996; Terziovskiv et al., 1997). The SMIs industries are classified as those industries with total workforce of less than 150 employees and the companies with annual sales not exceeding RM25 million (SMIDEC, 2002). From the each group 25 percent of industries were selected and asked over telephone to provided time and date for responses. But about 5 per cent of industries close or shifted their business as mentioned the address and telephone number by the FMM. Thus, finally 82 companies were selected and collected primary data through questionnaire.

Respondents were asked to indicate all relevant choices from a list of ten major barriers perceived by other researches that could demotivate the EC adoption. In addition, respondents asked other questions to identify Internet based activities were being used by the electronic manufacturing companies in Malaysia. Those questions included were, length of time the companies manufactured the electronic goods, year of Internet usage, their number of employees, types of companies. The structure of questionnaires follows the five point Likart Scale ranging from least important to most important was used to measured the expression of their perceived experienced on EC.

\section{Data Analysis Techniques}

Data were collected on demographic variables are processed and reported in percentage through the descriptive analysis. Descriptive analysis refers to the transformation to describe a set of factors that will make them easy to understand and interpret (Sekaran, 2000; Zikmund, 2000). $T$-test was carried out to determine if there is any significant difference on perceived barriers between different demographic groupings.

\section{Results and Analysis}

\section{Respondents Profile}

Table 1 shows the total profile of respondents considered for this study. The following sub-sections provide the discussion of the respondents profile.

\section{Internet Usage}

The respondents of this study were electronic manufacturing companies in Malaysia. With regards to the Internet usages, the sample population was divided into two groups, less than 5 years and more than five years of Internet usage. This survey shows that, less than 5 years Internet users are the largest portion of the sample with a total of 130 respondents ( 67.0 per cent). The other group, 5 years and above had 64 respondents ( 33.0 per cent).

\section{Types of Companies}

It is expected that multinational companies are the highest level of electronic manufacturing companies in Malaysia. This is because, most of the companies are multinational companies and they are selling their goods in the global markets. For this reason, consideration has also been given to provide response to the questions on types of companies. In the present study multinational companies are the highest level of respondents (58.3 per cent), followed by local companies (30.4 per cent) and joint venture companies (11.3 per cent).

\section{Period of Goods Manufactured}

The highest level of respondents from the 194 companies in the survey is the 7 years and above goods manufactured companies with a total of 139 companies ( 71.6 per cent), followed by the less than 7 years companies with a total of 55 companies (28.4 per cent).

\section{Size of the Companies (based on total employees)}

With regards to employees, Table 1 shows the two major groups that compose the sample. The small-scale industries are classified as those industries with total workforce of less than 150 employees. This group composed 
the highest portion of the sample, 123 (63.4 per cent). The second group was of those from large-scale industries with work force more than 150 employees. They comprised 71 (36.6 percent). Based on this sample, it is noted that the largest group of the respondents were those from the small-scale industries.

\section{Size of the Companies (based on annual sales)}

With regards to annual turnover, the sample population was divided into small-scale and large-scale industries. The small-scale industries are classified as those industries with annual turnover less than RM6,000,000. This group comprised largest respondents with a total of 112 (57.7 per cent). The large-scale industries group comprised of 82 companies ( 42.3 per cent). This section gives the support to the past section where company sizes are divided based on the employees. This study found that small-scale industries are the largest group of respondents for this research.

Table 1 Respondents Profile

\begin{tabular}{|c|c|c|c|c|}
\hline No & Demographic Variables & No. of Respondents & $\%$ & Cumulative \% \\
\hline \multirow[t]{3}{*}{1.} & Internet Users & & & \\
\hline & Less than 5 year & 130 & 67.0 & 67.0 \\
\hline & 5 years and above & 64 & 33.0 & 100.0 \\
\hline \multirow[t]{4}{*}{2.} & Types of Companies & & & \\
\hline & Local Companies & 59 & 30.4 & 30.4 \\
\hline & Multinational Companies & 113 & 58.2 & 88.7 \\
\hline & Joint Venture Companies & 22 & 11.3 & 100.0 \\
\hline \multirow[t]{3}{*}{3.} & Size of the Companies (based on total employees) & & & \\
\hline & Below 150 employees & 123 & 63.4 & 63.4 \\
\hline & Above 150 employees & 71 & 36.6 & 100.0 \\
\hline \multirow[t]{3}{*}{4.} & Periods of Goods Manufactured & & & \\
\hline & Less than 7 years & 55 & 28.4 & 28.4 \\
\hline & Above 7 years & 139 & 71.6 & 100.0 \\
\hline \multirow[t]{3}{*}{5.} & Size of the Companies (based on annual sales) & & & \\
\hline & Below RM6, 000,000 & 112 & 57.7 & 57.7 \\
\hline & Above RM6, 000,000 & 82 & 42.3 & 100.0 \\
\hline
\end{tabular}

\section{Activities on the Internet based EC.}

Table 2 shows the EC activities usage by the electronic manufacturing companies in Malaysia. This section also accomplishes the first specific objective of this study. There are many activities used by the Internet based EC in the businesses. Some main activities are discussed in this section.

Table 2 E-Commerce Applications

\begin{tabular}{lcc}
\hline \hline EC applications & Total companies & Percent of Cases \\
\hline Buying & 56 & $28.9 \%$ \\
Procuring & 79 & $40.7 \%$ \\
E-mail & 193 & $99.5 \%$ \\
Seeking Information & 190 & $97.9 \%$ \\
Selling & 41 & $21.1 \%$ \\
Distribution & 53 & $27.3 \%$ \\
Promotion & 78 & $42.2 \%$ \\
Direct Marketing & 34 & $17.5 \%$ \\
Advertising & 107 & $55.2 \%$ \\
Transactions & 73 & $37.6 \%$ \\
Public Relation (PR) & 62 & $32.0 \%$ \\
Customer Services \& Support. & 149 & $76.8 \%$ \\
\hline \hline
\end{tabular}


Respondents were asked to indicate the EC application used by the electronic manufacturing companies is Malaysia. For this study twelve activities were considered and they are as follows:

Off all the respondents more than 99 percent (99.5 percent, 193 companies) indicated e-mail as the main activities used by them. 97.9 percent (190 companies) respondents indicated that, they were using Internet based EC for seeking information purposes. A total 149 company (76.8 percent) indicated were using EC for customer service and support purposes. The 28.9 percent (56 companies) used EC for buying raw materials from other businesses or suppliers. Out of 194 companies 41 companies ( 21.1 percent) used both for selling and transactions purposes. Total 107 companies of 55.2 percent used EC as a medium of advertising their goods. Out of 194 companies, 78 companies used EC as a tool for promotion of goods ( 42.2 percent). Followed by 40.7 percent ( 79 companies), 37.6 percent (62 companies), 27.3 percent ( 53 companies) and 17.5 percent ( 34 companies) used EC for procuring, public relations (PR), distribution and direct marketing purposes respectively.

\section{Some major barriers and benefits of E-Commerce Adoption}

This section presents some major barriers faced by the companies in the E-Commerce business. Some major barriers for E-Commerce business are lack of security, lack of IT personnel, lack of privacy; hacker's intervention, insufficient telecommunication bandwidth; and high set up cost.

Table 3 shows the means and standard deviations to understand the problems. Respondents were asked to indicate these barriers on a 1 to 5 scale with 1 indicating the "most important", 2 indicating "important", 3 indicating "Neutral" 4 indicating "less important" and 5 indicating the "least important".

Table 3 Summary table of means and standard deviations of EC business.

\begin{tabular}{|c|c|c|}
\hline Barriers of E-Commerce Adoption & Means & Standard Deviation \\
\hline Lack of Security & 4.4654 & 0.6539 \\
\hline Lack of IT personnel & 3.5723 & 0.9377 \\
\hline Lack of privacy & 4.0818 & 0.9411 \\
\hline Hackers' Intervention & 3.4780 & 1.0053 \\
\hline Insufficient Telecommunication Bandwidth & 3.5157 & 0.9734 \\
\hline High set up cost & 4.4465 & 0.7173 \\
\hline
\end{tabular}

In this regard the statement with the highest means (M) score on problems were "Lack of Security" of business ( $\mathrm{M}=4.4654)$, "High set up cost" of E-Commerce business $(\mathrm{M}=4.4465)$, "Lack of Privacy" $(\mathrm{M}=4.0818)$, "Lack of IT personnel" (M=3.5723), "Insufficient Telecommunication Bandwidth" (M=3.5157), and "Hackers intervention" (Mean=3.4780),

\section{Major Barriers in Different Demographic Groupings}

In this section the outcome of the " $t$ " tests on the major barriers in different demographic groupings is presented. The purpose of this analysis is to investigate if there is a significant difference between the major barriers to adopt EC in Malaysian electronic manufacturing companies between different demographic groupings. A summary of major barriers and benefits is presented in the Table 3. That table shows the means and standard deviation to understand the major barriers in EC adoption. The following subsections discuss the $t$-test results of different groupings.

\section{Difference in barriers according to the period of Internet usage}

Table 4 displays the results of means, standard deviation and $t$ values of differences in means between respondents using the Internet for less than five years and above five years for major barriers. 
In this study, it appears that there is a significant difference between those using Internet less and more than five years are the barriers of "Lack of Privacy" as the $t$ value of these this barrier is more than the critical $t$ of 1.960 for the sample size of 194 and a $95 \%$ confident level.

This result is soundly supported by the study of Aldridge et al., (1997), Denning (1999), Sandarson \& Forcht (1996) and Mukty (2000). They had also stated that privacy concern have often been cited as one of the key reason to do not make business online, and hackers are the most rapidly growing threat to Internet worked machine.

Table 4

Results of $t$ tests for difference of major barriers of adopting EC between those using the Internet for less than five years and more than five years.

\begin{tabular}{||lccccc||}
\hline Barriers & $\begin{array}{c}\text { Period of Internet } \\
\text { Usage }\end{array}$ & N & Mean & SD & $\boldsymbol{t}$ value \\
\hline Lack of Security & Less than 5 years & 130 & 4.5154 & .6498 & 1.252 \\
& Above 5 years & 64 & 4.3906 & .6574 & 1.247 \\
Lack of IT personnel & Less than 5 years & 130 & 3.5846 & .9382 & .794 \\
& Above 5 years & 64 & 3.4688 & .9915 & .779 \\
Lack of privacy & Less than 5 years & 130 & 4.1769 & .8578 & 2.323 \\
& Above 5 years & 64 & 3.8438 & 1.0869 & 2.145 \\
Hackers' Intervention & Less than 5 years & 130 & 3.5154 & 1.0209 & 1.568 \\
& Above 5 years & 64 & 3.2656 & 1.0873 & 1.535 \\
Insufficient Telecommunication & Less than 5 years & 130 & 3.5462 & .9653 & 1.135 \\
bandwidth & Above 5 years & 64 & 3.3750 & 1.0312 & 1.110 \\
High set up cost & Less than 5 years & 130 & 4.4231 & .7246 & -.552 \\
& Above 5 years & 64 & 4.4844 & .7344 & -.549 \\
\hline
\end{tabular}

* Significant statistic

\section{Difference major barriers according to periods of electronic goods manufactured}

Table 5 displays the results of means, standard deviations and $t$ values of difference in means between groups according to periods of goods manufacturing for less than seven years and above seven years. In this regards, it was found that there is a significant difference between those two groups of companies producing goods less than and more than seven years in the barrier of "High set up cost", as the $t$ value of this variable is more than the critical $t$ value of 1.960 for the sample size of 194, and at a 95\% confident level. This result is clearly given the support by the study of Mukty (2000) studied barriers of EC adoption in Malaysian business sectors.

Table 5

Results of $t$ tests for difference of major barriers of adopting EC between those groups producing electronic goods for less than seven years and more than seven years.

\begin{tabular}{||lccccc||}
\hline \hline Barriers & $\begin{array}{c}\text { Period of goods } \\
\text { manufactured }\end{array}$ & N & Mean & SD & $\boldsymbol{t}$ value \\
\hline Lack of Security & Less than 7 years & 55 & 4.4000 & .7601 & -.995 \\
& Above years & 139 & 4.5036 & .6064 & -.903 \\
Lack of IT personnel & Less than 7 years & 55 & 3.4364 & 1.0674 & -1.009 \\
& Above 7 years & 139 & 3.5899 & .9074 & -.941 \\
Lack of privacy & Less than 7 years & 55 & 4.1273 & .7711 & .555 \\
& Above 7 years & 139 & 4.0432 & 1.0134 & .623 \\
Hackers' Intervention & Less than 7 years & 55 & 3.3091 & 1.1843 & -1.037 \\
& Above 7 years & 139 & 3.4820 & .9879 & -.954 \\
Insufficient Telecommunication & Less than 7 years & 55 & 3.4000 & 1.0818 & -.794 \\
bandwidth & Above 7 years & 139 & 3.5252 & .9504 & -.751 \\
High set up cost & Less than 7 years & 55 & 4.6545 & .5170 & 2.585 \\
& Above 7 years & 139 & 4.3597 & .7802 & 3.067 \\
\hline
\end{tabular}

* Significant statistic 


\section{Difference in major Barriers between Small-scale and Large-scale industries (based on employees).}

Table 6 displays the results of means, standard deviation and $t$ values of difference in means between small-scale and large-scale industries. All the $t$ values of the variables are less than critical $t$ value except of "High set up cost". As the $t$ value of this barrier is more than critical $t$ value of 2.576 for the sample size of 194 , and at a 99\% confident level. This finding strongly supported by the study of Mukty (2000) studied in Malaysian business context.

Table 6

Results of $\boldsymbol{t}$ tests for difference of major barriers of adopting EC between small-scale and large-scale industries (based on employees)

\begin{tabular}{||lccccc||}
\hline \hline Barriers & Type of the company & $\mathbf{N}$ & Mean & SD & $\boldsymbol{t}$ value \\
\hline Lack of Security & Small-scale & 123 & 4.4797 & .6446 & .152 \\
& Large-scale & 71 & 4.4648 & .6725 & .151 \\
Lack of IT personnel & Small-scale & 123 & 3.5285 & .9437 & -.343 \\
& Large-scale & 71 & 3.5775 & .9807 & -.340 \\
Lack of privacy & Small-scale & 123 & 4.1220 & .8924 & 1.061 \\
& Large-scale & 71 & 3.9718 & 1.0415 & 1.018 \\
Hackers' Intervention & Small-scale & 123 & 3.4553 & 1.0182 & .389 \\
& Large-scale & 71 & 3.3944 & 1.1016 & .381 \\
Insufficient Telecommunication & Small-scale & 123 & 3.4878 & .9697 & -.039 \\
bandwidth & Large-scale & 71 & 3.4930 & 1.0264 & -.034 \\
High set up cost & Small-scale & 123 & 4.5691 & .6151 & 3.252 \\
& Large-scale & 71 & 4.2254 & .8484 & 2.990 \\
\hline
\end{tabular}

* Significant statistic

\section{Difference in major barriers between small-scale and large-scale industries (based on the annual turnover)}

Table 7 shows the results of means, standard deviations and the $t$ values of differences in means between small-scale and large-scale industries for major barriers in adopting the Internet based EC.

It appears that most of the $t$ values of barriers are less than critical $t$ value except for the barrier of "High set up cost". The critical $t$ value of this analysis is considered of 2.576 for the sample size of 82 and at a $99 \%$ confident level. This may be due to inadequate of funds. It is the most important factors to build the appropriate infrastructure of EC business. Some companies would find it easier to adopt the EC only is grants/subsidieries are given. This is because EC is quite expensive to start with; as a result, business on the Internet should be funded using business models such as advertising and sponsorship (Clarke, 1998).

Table 7

Results of $t$ tests for difference of major barriers of adopting EC between small-scale and large-scale industries (based on annual turnover).

\begin{tabular}{|c|c|c|c|c|c|}
\hline Barriers & $\begin{array}{l}\text { Type of the } \\
\text { company }\end{array}$ & $\mathbf{N}$ & Mean & SD & $t$ value \\
\hline \multirow[t]{2}{*}{ Lack of Security } & Small-scale & 112 & 4.4732 & .6431 & -.025 \\
\hline & Large-scale & 82 & 4.4756 & .6708 & -.025 \\
\hline \multirow[t]{2}{*}{ Lack of IT personnel } & Small-scale & 112 & 3.5714 & .9272 & .426 \\
\hline & Large-scale & 82 & 3.5122 & .9968 & .421 \\
\hline \multirow[t]{2}{*}{ Lack of privacy } & Small-scale & 112 & 4.1429 & .8367 & 1.302 \\
\hline & Large-scale & 82 & 3.9634 & 1.0823 & 1.252 \\
\hline \multirow[t]{2}{*}{ Hackers' Intervention } & Small-scale & 112 & 3.4911 & .9863 & .902 \\
\hline & Large-scale & 82 & 3.3537 & 1.1262 & .884 \\
\hline Telecommunication & Small-scale & 112 & 3.5536 & .9308 & 1.053 \\
\hline \multirow{2}{*}{ Telecommunication } & Large-scale & 82 & 3.4024 & 1.0524 & 1.034 \\
\hline & Small-scale & 112 & 4.5714 & .6397 & 2.926 \\
\hline & Large-scale & 82 & 4.2683 & .8019 & 2.827 \\
\hline
\end{tabular}

* Significant statistic 


\section{Conclusion and discussion}

This study have shown that many barriers prevent the electronic manufacturing companies from adopting electronic commerce, which are mainly, security, lack of set-up cost, and hackers intervention. In common with previous research of EC users (Mukty, 2000), security remains the prime concern of EC users. First concern of security is that their payment details such as credit card number. To overcome the worry about security of payment company can invest more in providing secure sites. The second security worry was that unauthorized access to their computer by hackers. To overcome this problem users must protect themselves by using robust firewalls.

The empirical findings reveal that doing business over Internet involves high start-up cost. In fact it is costly to set-up business electronically, because so many technological appliances are involved. Computers are quite expensive to buy, limited maintenance facility issue to take advantage of EC. This issue is really affecting small businesses. Therefore, in order to attract and motivate in adopting EC, the government has to support this sector fully by providing bank loans or subsidiaries.

Although the survey is concentrated on a particular industry and particular area in Malaysia, the results are generally consistent with previous research. The findings indicate that much still needs to be done before EC expands to the 'mass-market'.

\section{References}

1. Aldridge, A, White, M., Forcht, K., 1997, "Security considerations of doing business via the Internet: cautions to be considered", Internet Research, Vol 7, No 1.

2. Bauman, B.M., Forcht, K.A. \& Thomas, D.M., 1996, "Internet Security, privacy and legal considerations", Proceedings of Pan-Pacific Conference XIII in Chiba, Japan: pp. 255-257.

3. Churchill, G. A. (1991), Basic Marketing Research, Chicago, Dryden Press, USA.

4. $\quad$ Denning, D.E., 1999, Information Warfare and Security, Addision-Wesley, London.

5. Ghobandian, A. and Gallear, D. N., 1996, Total Quality Management in SMEs, Omega, vol 24, no 1, pp. 83-106.

6. Haksever, C., 1996, "Total Quality Management in the Small Business Environment”, Business Horizon, vol 39, March-April, pp. 33-40.

7. Hamid, A.B.A and Baharun, R. (2002), "Perception of E-commerce: A Survey on Malaysia Based Small and Medium Entrepreneurs", Paper presented at Academy of Marketing Annual Conference, Nottingham, 2-5 July.

8. Miles, M.B. and Huberman, M.A (1994), Qualitative Data Analysis, Sage Publications, London.

9. Mukty, N. A., 2000, "Barriers to Putting Business on the Internet in Malaysia", The Electronic Journal on Information Systems in Developing Countries, Vol 2, Num 6.

10. Sarderson, E., and Forcht K. A., 1996, "Information security in business environments", Information Management \& Computer Security, Vol 4, No 1.

11. Sekeran, U., 2000, Research Methods for Business: A Skill-Building Approach, Third Edition, John Wiley \& Sons, Inc.

12. Small Medium Industries Development Corporation (SMIDEC), Malaysia, 2002, E-Manufacturing Grant,

13. Steinfield, C. \& Klein, S., 1999, "Local vs. global issues in electronic commerce", Electronic Markets, vol 9, pp. 1-6.

14. Terziovski, M., Samson, D. \& Dow, D., 1997, "The Business Value of Quality Management Systems Certification-Evidence from Australia and New Zealand”, Journal of Operations Management, vol 15, no 1, pp. 1-18.

15. Udo, G. J., 2001, "Privacy and security concerns as major barriers for e-commerce: a survey study", Information Management \& Computer Security, Vol 9, Issue 4.

16. Zikmund, W. G. 2000, Exploring Marketing Research, $7^{\text {th }}$ ed, Dryden Press, Fort Worth. 